\title{
The turn of the screw: sobre Henry James, William James, cérebros e fantasmas
}

\author{
Guilherme Gutman
}

A novela The turn of the screw, de Henry James, vem suscitando interpretação vária desde sua aparição em 1898. Como se pode esperar de toda obra suficientemente rica, algo nela - talvez o estilo refinado de James ou as tonalidades de colorido afetivo emprestadas aos personagens; talvez a complexidade dos climas instaurados ou apenas o teor do tema explorado - permite que cada um a leia de modo diverso. Já nas primeiras linhas, o escritor leva o leitor a paragens misteriosas.

A história nos mantivera em suspense, em torno do fogo, mas, à parte a óbvia reflexão de que era horrível, como essencialmente deve ser toda história estranha contada, numa véspera de Natal, em uma velha casa, não me lembro de que sobre ela se fizesse qualquer comentário, até que alguém se aventurou a dizer que era o único caso em que tal coisa acontece a uma criança. Tratavase, posso dizê-lo, de uma aparição ocorrida numa casa tão velha como aquela em que nos achávamos reunidos - aparição, de horrível espécie, a um menino de pouca idade que dormia no aposento de sua mãe. […]

- Concordo inteiramente, quanto ao que diz respeito ao fantasma [...], ou o que quer que seja, que o fato de haver aparecido, em primeiro lugar, a um menino de tão tenra idade lhe confere uma característica particular. Mas não é a primeira ocorrência de tão encantadora espécie a acontecer a um menino, segundo sei. Se uma única criança aumenta a emoção da história e dá outra volta ao parafuso, que diriam os senhores de duas crianças?

- Diríamos, por certo - exclamou alguém -, que dariam duas voltas! E, também, que gostaríamos de saber o que aconteceu.*

(James, Henry. A outra volta do parafuso [1898]. São Paulo: Abril Cultural, 1980: 123.4).

No prólogo, do qual a citação acima é parte, estabelece-se a moldura da história: um homem, após as mortes de seu irmão e cunhada na Índia, passa a tutor do casal de sobrinhos. Sem a menor aptidão para os atributos práticos e afetivos de uma paternidade acidental, o tio instala as crianças em uma casa de campo em Bly, deixando-as aos cuidados diretos de uma 
jovem preceptora, que, em dado momento, morre em circunstâncias misteriosas. Diante do fato fúnebre, o tio contrata uma nova preceptora, também jovem e bonita como a anterior, para a educação e orientação das crianças.

$\mathrm{O}$ isolamento em Bly, intensificado pela "condição principal” imposta pelo tio, que era a de não ser nunca incomodado, é fundamental para a criação da atmosfera neblinosa em que a história se desenvolve, na verdade um relato em tom de diário escrito pela nova preceptora. Nesse relato, há, predominantemente, a presença das crianças, de uma empregada da casa e, é claro, da própria autora do manuscrito, sendo os outros personagens figuras muito apagadas, quase ausências. Mas, pouco a pouco, como a bruma, uma inquietude, intensificada e matizada ao longo da novela, insinua-se pelas páginas do diário, anunciando os primeiros sinais da presença de outros personagens mais sinistros.

[...] inquietude que, antes do amanhecer, me fez levantar várias vezes do leito e andar pelo quarto, para compenetrar-me mais do ambiente, observar, da janela, a pálida aurora estival, examinar as outras partes da casa que os meus olhos podiam distinguir, e escutar, enquanto as últimas sombras da noite se desvaneciam, os primeiros trinados dos pássaros, a possível repetição de um ou dois sons menos naturais que vinham não de fora, mas de dentro, e que eu supunha ter ouvido. Houve um momento em que julguei reconhecer, fraco e distante, um grito de criança; outro em que estremeci, quase conscientemente, ante o que me pareceu um ruído de passos leves atrás da porta. Mas tais idéias não eram bastante nítidas para que eu não pudesse afastá-las - e foi somente à luz, ou, talvez o dissesse melhor, somente devido à obscuridade dos acontecimentos subseqüentes, que isso me acode à memória.*

Há, na hesitação e na correção do curso da última frase "e foi somente à luz, ou, talvez o dissesse melhor, somente à obscuridade dos acontecimentos subseqüentes" ${ }^{1}-$, um valor ana-

${ }^{1}$ Outros tradutores de The turn of the screw encontraram soluções diferentes para o trecho acima traduzido por Brenno Silveira e analisado por nós. Na tradução de Olívia Krahenbuhl, lê-se: “À luz - ou antes, à sombra - de acontecimentos ulteriores, que elas retornaram à minha lembrança” (James, Henry. A volta do parafuso. São Paulo: Clube do Livro, 1987: 20). Na de Chico Lopes, temos: "À luz, ou à sombra, dos fatos subseqüentes, que agora retornam à minha memória” (James, Henry. $A$ volta do parafuso. São Paulo: Landmark, 2004: 21). Na língua original: "In the light, or the gloom, I should rather say, of the other and subsequent matters that they now come back to me" (James, Henry. The turn of the screw. New York: Taplinger: 445). 
lítico maior do que pode parecer a um leitor desatento. A memória dos acontecimentos "à luz" de alguma coisa sugere que a narradora desse trecho é orientada pela atividade de uma consciência intelectualizada que esclarece os fatos pela racionalidade e pela clareza mental que lhe deveriam ser inerentes. Mas a hesitação e o desvio do curso do pensamento sugerem algo bem distinto. A inflexão da frase, por assim dizer, toma o leitor pela mão e o leva a um lugar distante da presença de qualquer atividade racional: aos labirintos pouco iluminados da memória da nova preceptora e "à obscuridade dos acontecimentos subseqüentes".

Da sugestão de um sobrenatural mais diáfano, a história toma, a partir de certo ponto, um sentido fantasmagórico franco, como o comprova a sucessão de aparições sobrenaturais à preceptora e, possivelmente, às crianças também.

Primeiro, a aparição de um criado de quarto que, antes de morrer, havia desenvolvido uma intimidade peculiar com uma das crianças:

Houve um momento em que fiquei atenta a escutar, lembrandome da vaga sensação que tive, na primeira noite, de que havia algo indefinidamente ativo na casa [...]

A aparição havia alcançado o patamar existente no meio da escada, achando-se, portanto, no lugar mais próximo à janela, quando, ao ver-me, deteve-se e fitou-me exatamente como me havia observado da torre e do jardim. Conhecia-me tão bem como eu o conhecia - e, assim, na fria e imprecisa claridade matinal, entre $\mathrm{o}$ alto resplendor da janela e o brilho, embaixo, das escadas enceradas, de carvalho, encaramo-nos com mútua intensidade. $[\ldots]$

Ele [...] era humano, tão humano como a gente se encontrar a sós, a horas mortas, numa casa adormecida, com um inimigo, um aventureiro ou um criminoso. [...] $\mathrm{O}$ instante se prolongou a tal ponto que pouco faltou para que eu começasse a duvidar se estava viva ou não. Não me é possível descrever o que se passou logo após, salvo dizer que o próprio silêncio - que era, de certo modo, um atestado de minha energia - transformou-se no elemento em que vi a figura desaparecer, em meio do qual a vi, claramente, voltar-se, como poderia ter visto o miserável fazer ao receber uma ordem; depois, com os olhos fixos em suas costas, que nenhuma horrorosa corcova poderia haver desfigurado mais, vi-o descer os degraus e mergulhar na sombra em que se perdia a curva da escada."

E, depois, a aparição da preceptora morta:

Sentada a minha própria mesa, à luz do meio-dia, vi uma pessoa 
[...]. Revelava esforço a maneira pela qual as suas mãos, com evidente cansaço, sustinham a cabeça, enquanto os braços se apoiavam à mesa. Não obstante, enquanto eu fazia essa observação, sua atitude persistia estranhamente, apesar de minha chegada. Depois mudou de atitude, o que fez com que sua identidade, num relâmpago, se revelasse. Ergueu-se, não como se houvesse notado a minha chegada, mas com uma grande e indescritível melancolia, cheia de indiferença e desapego, e, a poucos passos de distância, pude ver a minha vil antecessora. Ali estava à minha frente, desonrada e trágica; mas, no momento em que a fixei, para reter sua imagem na memória, a horrível aparição se desvaneceu. Negra como a noite em seu vestido preto, sua macilenta beleza e seu pesar, olhou-me o bastante para dar-me a entender que o seu direito de sentar-se à minha mesa era tão válido como o meu de sentar-me à dela. ${ }^{*}$

Talvez seja difícil extrair dos trechos citados, embora relativamente longos, a ambiência de mistério, morbidez e terror sugerida aos leitores de The turn of the screw. Alguns jornais da época em que a novela foi lançada, manifestaram opiniões extremadas, talvez como uma primeira reação à violência que o texto produziu nos leitores ${ }^{2}$. E mesmo H. James teria provado de seu próprio veneno, ao experimentar "parte do terror

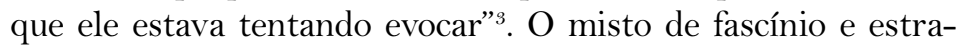

${ }^{2}$ Encontramos em Felman (1982) alguns exemplos representativos de tais reações: "A história é decididamente repulsiva", afirma The Outlook [...]. The Independent vai ainda mais longe: "The turn of the screwé a mais incorrigivelmente má história que jamais se leu em toda literatura, antiga ou moderna. Como o Sr. James pode, ou como poderia qualquer homem ou mulher, escolher realizar tal estudo da infernal devassidão humana [...]. O estudo, embora exiba o talento do Sr. James de modo claro, afeta o leitor provocando um asco que não pode ser expresso. [...] A imaginação humana não pode ir mais longe na infâmia, a arte literária não pode ser usada com mais refinada sutileza de profanação espiritual”. Cf. Felman, Shoshana. "Turning the screw of interpretation". Em: Literature and psychoanalysis Baltimore: Johns Hopkins, 1982: 97. Mas não apenas anônimos manifestaram o impacto experimentado. Curtis cita o seguinte trecho de uma carta de Oscar Wilde: "É uma pequena história maravilhosa, lúgubre e maligna, como uma tragédia elizabetana. Eu estou muito impressionado com ela". Cf. Curtis, Anthony. "Introduction \& notes". Em: James, Henry. The Aspern papers and the turn of the screw. New York: Penguin, 1984: 17. Pode-se obter algumas informações sobre a relação entre Henry James e Oscar Wilde em Ellmann, Richard. "Henry James entre os estetas”. Em: Ao longo do riocorrente. São Paulo: Companhia das Letras, 1991.

${ }^{3}$ Ainda de acordo com Edel, duas historietas cercam a elaboração de The turn of the screw. A primeira endossaria o medo experimentado por Henry: "Edmund Gosse afirmou que James disse a ele, 'Eu tive que corrigir as provas de minha estória de fantasmas na noite passada e, quando eu terminei, eu estava tão amedrontado que tive medo de subir as escadas”. A segunda historieta contrariaria o 
nheza que as histórias de fantasmas costumam provocar parece ganhar sua expressão plena na escrita envolvente de James.

Mais uma vez, o leitor afoito deve ser refreado em sua pressa. Como na análise do efeito de chiaroscuro utilizado por H. James para denotar a mudança de curso do pensamento da nova preceptora, que, como se viu, vai de um ponto iluminado pela razão a outro "à sombra" e, portanto, premonitório da "obscuridade dos acontecimentos subseqüentes", James novamente utiliza notações de luz de forma simbólica. Dessa vez, o contraste é notado entre as condições de iluminação e sombreamento presentes nos trechos acima, referentes à aparição do criado de quarto e à aparição da preceptora morta. Na descrição da primeira aparição, há a utilização de termos, frases e expressões sugestivas de escuridão - "a vaga sensação" da "primeira noite"; "na fria e imprecisa claridade matinal, entre o alto resplendor da janela e o brilho, embaixo, das escadas enceradas" - e que, assim, mergulham e encerram o "fantasma" em um mundo sobrenatural. A nova preceptora chega a duvidar "se estava viva ou não", mas é salva pelo "silêncio [...] de certo modo, um atestado de (sua) energia", que afasta a aparição, como quem enxota um ser maligno de volta às trevas de onde veio ("vi-o descer os degraus e mergulhar na sombra em que se perdia a curva da escada"). Ela estava "viva", isto é, ela estava "sã", no sentido de que ela sobrevive à aparição, até então algo heterogêneo a ela, como o contraste e a separação nítida entre luz e sombra. Na descrição da segunda aparição - a da preceptora morta - ao contrário do que ocorre em relação à primeira, a claridade que incide sobre o objeto fantasmagórico é plena: "à luz do meio-dia, vi uma pessoa”. Aqui, não há dúvida sobre a existência e presença do fantasma, tendo a luz reveladora e forte de um dia claro, o efeito, perverso nesse caso, de insinuar que a obscuridade está não mais na aparição que surge em contornos nítidos,

poder terrificante da novela: "William Lyon Phelps citou James como tendo dito 'Eu pretendia assustar o mundo inteiro com essa história', e descrito como ele a ditou para o jovem McAlpine (o taquígrafo a seu serviço). 'Este escocês de ferro não revelou a menor sombra de sentimento. Eu ditei para ele frases que, pensei, o fariam saltar da cadeira; ele as redigiu como se fossem geometria; e sempre que eu parava para vê-lo desmoronar, ele dizia num tom seco: 'Em seguida”. Cf. Edel, Leon. "Introduction \& headnotes". Em: James, Henry. Stories of the supernatural. New York: Taplinger, 1970: 426. Apesar de encantadoras, Edel desconfia da veracidade das historietas. 
plena e "negra como a noite em seu vestido preto", mas no sujeito que percebe o objeto". É precisamente este o ponto de início do terror extremo, da vertigem desatinada, do enlouquecimento irremediável ou, em outro viés de compreensão, de contato da nova preceptora com qualquer coisa que escapa à sua racionalidade: a sombra já não esconde os fantasmas, mas paira fixa e ameaçadora sobre ela.

Mas que mistérios tem Bly? Há ao menos dois conjuntos de interpretações dessa obra, que, como dissemos, já foi amplamente analisada. Esses dois conjuntos são representativos da, assim chamada por Parkinson (1991), “controvérsia aparicionista/não aparicionista" ${ }^{5}$ em torno da qual gravitou toda a fortuna crítica da peça literária de James. O primeiro deles destaca o caráter fantástico da novela, tipo de interpretação que, a nosso ver, é favorecida por três grupos de acontecimentos presentes na novela. Primeiramente, por discussões entre os personagens em torno da veracidade das vivências experimentadas pela nova preceptora. Serão vivências ilusórias, meras fantasias de uma jovem sugestionável ou, de fato, experiências oriundas do além? Em seguida, pela tentativa de estabelecimento das causas, ou razões, do aparecimento das visões. E, enfim, pela presença de uma espécie de embate espiritual entre a força sobrenatural que embala as aparições e a força de vontade dos personagens terrenos.

Esses acontecimentos vão levando o leitor para o clima de uma história fantástica e, por assim dizer, convencendo-o da plausibilidade de algo pouco plausível: o retorno ao mun-

${ }^{4}$ Em Edel encontra-se uma linha de interpretação que parece coadunar-se à nossa. Diz ele: "Os fantasmas de James se locomovem em plena luz do dia. Ele cria uma atmosfera lúgubre, fazendo o extraordinário ocorrer ao lado do comum. Dessa forma, o terror é intensificado com considerável veemência. O que James adicionou ao conto fantástico foi na realidade uma série de profundos estudos acerca das modalidades da angústia humana - da capacidade que têm os homens para temer a si próprios, com fantasmas de sua própria invenção”. Edel, Leon. Henry James. São Paulo: Martins, 1960: 54.

${ }^{5}$ A respeito dessa terminologia, Parkinson esclarece: "Eu uso o termo aparicionista para me referir a interpretações nas quais os fantasmas são vistos como reais - aparições verídicas ou manifestações de alguma realidade paranormal existindo independentemente da apreensão subjetiva da governanta. Eu uso o termo não-aparicionista para me referir a interpretações nas quais os fantasmas são vistos como não verídicos, meras alucinações subjetivas (sic) da governanta. Essa é a terminologia standard no conjunto histórico crítico a The Turn of the Screw". Parkinson, Edward. The turn of the screw: a history of its critical interpretations 1898-1979. Disponível em www.turnofthescrew.com. 
do de pessoas já mortas. De acordo com Paes em sua leitura de Todorov, os passos vacilantes do leitor, que o levam e o trazem de volta ao caminho do convencimento interno da veracidade dos eventos ficcionais, são a essência do adjetivo "fantástico literário" aplicado ao tipo de narrativa da novela. O fundamental, portanto, é a presença de "uma dúvida insolúvel entre uma explicação natural e uma explicação sobrenatural para os sucessos narrados - sucessos cuja estranheza põe perigosamente em xeque a própria noção de realidade e verossimilhança que o leitor compartilha com o comum das pessoas"*.

Essas idas e vindas entre a crença e a descrença na veracidade dos eventos ficcionais mantêm no leitor o sentimento de inquietude tão característico do estado de dúvida. Em Todorov, esse estado de trânsito entre a certeza e a incerteza é fundamental para a caracterização do que seja "a fórmula geral da narrativa fantástica”. Segundo ele, essa fórmula:

se caracteriza não pela simples presença de acontecimentos sobrenaturais, mas pela maneira como os percebem o leitor e as personagens. Um fenômeno inexplicável acontece; para obedecer a seu espírito determinista, o leitor se vê obrigado a escolher entre duas soluções: ou atribuir esse fenômeno a causas conhecidas, à ordem normal, qualificando de imaginários os fatos insólitos; ou então admitir a existência do sobrenatural, trazendo pois uma modificação ao conjunto de representações que formam sua imagem do mundo. O fantástico dura o tempo dessa incerteza; assim que o leitor opta por uma ou outra solução, desliza para o estranho ou para o maravilhoso.*

Portanto, ler Todorov com rigor equivale a assumir o ponto de vista de que, ao se optar pela perspectiva "aparicionista", desliza-se do campo propriamente fantástico até o aconchego do rincão plácido, embora habitualmente morno, da ausência de dúvida. Uma parte significativa do encanto de The turn of the screw é, como se diz, nunca fechar questão, isto é, não permitir que o leitor decida facilmente, sustentando assim a experiência do fantástico.

O segundo conjunto de interpretações segue uma linha bem distinta da anterior, podendo ser chamado de psicologizante ${ }^{6}$.

${ }^{6}$ Wallace Leal V. Rodrigues, um dos tradutores brasileiros de The turn of the screw, adota uma posição interpretativa explicitamente espírita, ou kardecista, opondo-se energicamente à interpretação psicologizante. No prefácio à sua tradução da obra de James, diz: "Finalmente este livro vai para onde, desde há muito
" (Paes, José. "Até o último fantasma: a representação do fantástico em Henry Ja. mes". Em: James, Henry. Até o último fantasma: contos fantásticos. São Paulo: Companhia das Letras: 174.)

- (Todorov, Tzvetan. As estruturas narrativas. São Paulo: Perspectiva, 1969: 191-2.) 
" (Felman, Shoshana. "Tur ning the screw of inter. pretation". Ob. cit.: 97).

(Dupee, F. Henry James. New York: Delta, 1965: 159).
Uma referência obrigatória, pelo pioneirismo, é Edmund Wilson, que, em 1934, "pela primeira vez sugeriu explicitamente que The turn of the screw não é, na verdade, uma estória de fantasmas, mas uma estória de loucura, o estudo de um caso de neurose"* Como destacou um dos comentadores da obra do escritor, "em geral os fantasmas de James não são gratuitos como tendem a ser no conto usual de terror. Como aqueles de Shakespeare, eles aparecem apenas para pessoas a quem a angústia tenha primeiro qualificado para a experiência"*. Seguindo essa diretriz, alguns críticos privilegiaram a busca de um sentido psicológico para as vivências incomuns experimentadas pela nova preceptora. Basearam-se, talvez de modo excessivamente esquemático, na conviç̧ão de que haveria algum tipo de conflito interno na base das angústias e, nesse caso, das pseudo-alucinações ou alucinações visuais experimentadas pela protagonista ${ }^{7}$. $\mathrm{O}$ trecho seguinte, ao fazer referência ao apaixonamento apenas insinuado entre a nova preceptora e o tio das crianças, ilustra bem esse segundo conjunto analítico.

Um dos pensamentos que me acompanhavam [...] era que seria encantador como um conto encantador se eu me encontrasse subitamente com alguém. Alguém apareceria, de repente, na volta do caminho e ficaria parado a fitar-me, sorrindo, com ar de aprovação. Não pedia mais do que isso: pedia apenas que ele soubesse, e a única maneira de estar certa de que ele o sabia teria sido lê-lo na bondosa expressão de seu belo rosto. Isso estava claramente presente em minha imaginação - isto é, o rosto - quando, na primeira dessas ocasiões, no fim de um longo dia de junho, detive-me subitamente, ao sair de trás de uns arbustos e deparar com a casa à minha frente. $\mathrm{O}$ que me pregou no chão - chocando-me muito mais do que qualquer outra visão o poderia ter feito - foi a sensa-

tempo, deveria estar: as estantes espíritas. Aclamado pela crítica como uma obra prima de terror, ao ser alçada entre os clássicos da literatura norte-americana, de imediato e apressadamente foi classificada como uma obra pré-freudiana. Nada mais inexato, mesmo que lembrassem - mais propriamente - de Carl Gustav Jung. O importante seria evitar que obra tão essencial como esta, fosse catalogada na literatura psíquica”. Rodrigues, Wallace Leal V. "Prefácio”. Em: James, Henry. Os inocentes. Matão: O Clarin, 1980: I.

${ }^{7}$ Um exemplo desse tipo de análise crítica é oferecido por Mc Eldery Jr. em trechos como o seguinte: "Em síntese, a história da [preceptora] parece ser o relato de uma mulher nas garras da alucinação, descrita tão vivamente que parece ser verdadeira, não somente a ela, mas à governanta da casa, ao leitor...”. Mc Eldery Jr., Bruce. Henry James. Rio de Janeiro: Lidador, 1966: 132. 
ção de que a minha fantasia, num abrir e fechar de olhos, tornarase real. Lá estava ele!... mas muito no alto, além do relvado, no próprio topo da torre [...].

Lembro-me de que essa figura produziu em mim, no claro crepúsculo, dois assomos distintos de emoção, que foram, nitidamente, o sobressalto da minha primeira e, depois, da minha segunda surpresa. A segunda foi a violenta percepção do erro da primeira: o homem que surgia ante os meus olhos não era a pessoa que eu, precipitadamente, supusera. Isso me deixou tão perplexa e confusa que ainda hoje, depois de todos estes anos, não posso encontrar uma surpresa que se lhe compare.*

Aqui se tem, de um lado, o desejo da jovem pelo olhar admirado e amoroso do seu objeto de paixão e, de outro, como efeito do conflito egóico, a fabricação psíquica da primeira aparição fantasmagórica. De um lado, um desejo que, além de ir de encontro à realidade, sofre resistências de ordem moral, produzindo, do outro, vivências ilusórias e idéias deliróides de cunho místico.

O que nos parece, no entanto, é que esse tipo de interpretação peca pela tendência à compreensão dos movimentos psicodinâmicos da personagem em termos demasiado simples, algo como exercícios ligeiros de uma psicanálise de almanaque. Afinal, uma coisa é destacar a fineza da pena de James na constituição psicológica de seus personagens suas ambigüidades, contradições e particularidades psíquicas - e notar que a novela em questão é mais que um excelente conto de terror. Outra, esfacelar sob o peso de um Freud pasteurizado a porcelana jamesiana, delicadamente moldada por um raro senso de proporção formal. Um dos problemas presentes nas análises de linha psicológica é, quase sempre, aplainar com interpretações técnicas a densidade dos personagens. Posto que parte desse efeito de densidade psicológica é obtido pela presença de imprecisões e situações literárias não inteiramente resolvidas, lançar sobre elas um olhar dissecador redunda na dissolução da arquitetura ficcional e, com ela, da densidade e do mistério. Além disso, olhar para a nova preceptora e ver apenas uma "histérica tola” equivale a notar "apenas uma das várias possibilidades de uma história que parece ter como intenção lidar mais com possibilidades que com fatos" ". Os riscos de deitar a personagem, ou o autor, no divã de um psicanalista são, naturalmente, enormes. Vale notar que o próprio Henry co-
( James, Henry. A outra volta do parafuso. Ob. cit.: 148-9.)
"(Dupee, F. Henry James. Ob. cit.) 
"(Edel, Leon. "Introduction \& headnotes". Ob. cit.: 432-3).

* (Paes, José. "Até o último fantasma: a representação do fantástico em Henry Ja. mes". Ob. cit.)
"(Edel, Leon. "Introduction and "The tales". Em: Edel, L. Henry James: a collection of critical essays. Englewood Cliffs: Spectrum, 1963: 2.) nhecia psicologia ${ }^{8}$ e poderia, caso fosse esse o seu interesse, dispensar os psicanalistas de plantão e arquitetar, ele mesmo, em seus prefácios, cartas e anotações, referências técnicas ao sofrimento psíquico da personagem. De acordo com Edel, "o que James revelou (em The turn of the screw) foi sua compreensão ampla do que seja 'fantasia', no sentido em que a psicanálise usa atualmente o termo". Todavia, ainda de acordo com Edel, a novela de James estaria referida à tradição literária das irmãs Brontë9. "Muito de sua atmosfera e mesmo da linguagem", prossegue Edel, "representa a tentativa de James de reter tal tradição em sua estória. É às irmãs Brontë, mais que ao movimento psicológico moderno em seu estado nascente em Viena, que essa estória deve ser referida - e à compreensão, do próprio James, do modo pelo qual as pessoas têm sonhos e fantasias, incorporando-os em seus "sensos de realidade"*.

Segundo Paes, certas características da escrita de Henry James, como a presença profusa de alusões, sugestões, obliqüidades e subentendidos, tornam seus romances, novelas e contos alvos fáceis para espíritos interpretativos.* Como nota Edel, o conjunto de análises críticas sobre a obra de James é como uma colcha de retalhos, uma miscelânea de imagens. "As contradições estão por todo lado, e as imagens cancelam umas as outras [ [...]. Mesmo quando trabalhos isolados são examinados, não há concordância. [...] A governanta de The turn of the screw é valente, esplêndida, corajosa e tem grande autoridade; mas ela é obcecada, assombrada, reprimida sexualmente e neurótica - em resumo, total e completamente louca"*. Naturalmente, são possíveis interpretações de caráter psicoló-

${ }^{8}$ Em apoio a essa informação, temos em Edel a seguinte passagem em seu prefácio histórico e crítico a The turn of the screw: "Deve-se levar em consideração a familiaridade de Henry James com o conhecimento psicológico de seu tempo, com a obra de Charcot, com as investigações de seu irmão, e o fato de que ele foi uma testemunha, em sua própria família, da prolongada doença mental que precedeu a morte de Alice James (sua irmã), e das medidas terapêuticas utilizadas pelos médicos eminentes que a trataram". Edel, Leon. "Introduction \& headnotes". Ob. cit.: 428). Afora isso, é um estímulo à imaginção pensar que psicanalista teria sido Henry James.

${ }^{9}$ Curtis relaciona uma das passagens de The turn of the screw ao romance Jane Eyre, de Charlotte Brontë, mas, de nossa parte, resta a impressão de que o clima geral do livro se aproxima mais do romance único de outra das irmãs Brontë, Wuthering heights, de Emily Brontë. Cf. Curtis, Anthony. "Introduction \& notes". Ob. cit. 
gico que não incorram nos perigos analíticos descritos. Um caminho promissor para interpretações preocupadas em preservar a junção delicada entre recursos literários formais e a profundidade psicológica de seus personagens é apontado por Paes, quando ensina que "o [ [...] realismo de James é psicológico: move-se a maior parte do tempo na interioridade dos personagens para analisar as impressões ali deixadas pelo mundo dos fatos e esmiuçar as componentes morais dos seus juízos e opções"*.

Alguns comentadores, como Fadiman, sem se afastarem do conjunto de interpretações psicologizantes, são mais sutis, limitando-se a ressaltar em James, "à luz do que Freud nos ensinou", toda sua "extraordinária percepção das pulsões recônditas, ou mesmo sinistras, de homens e mulheres"*.

Outros, como Martin, afastam-se um pouco deste pólo interpretativo, em direção a uma compreensão calcada em bases biológicas." De acordo com Sacks, Martin postulou que as alucinações da governanta seriam crises epilépticas parciais e que este autor "fez a intrigante insinuação de que Henry James se teria encontrado com Hughlings Jackson, discutido tais crises com ele e utilizado tal conhecimento na descrição das estranhas aparições em $A$ volta do parafuso"**

Em uma linha psicanalítica filiada ao desenvolvimento teórico operado por Lacan, Felman obtém alguns acertos na correlação entre passagens de The turn of the screw e conceitos freudianos como os de transferência e de repetição. Contudo, mais que a "releitura (da novela de H. James) à luz do insight lacaniano", há, no artigo dessa autora, algumas observações interessantes de caráter geral. Em primeiro lugar, a posição metodológica de que, qualquer que seja o viés da análise, o foco da leitura deve estar sobre o texto, e não sobre os personagens ou sobre o autor. Essa recomendação, por si só, afastaria uma série de equívocos interpretativos que, em se tratando de leituras psicanalíticas, Freud classificaria como "psicanálise selvagem"*. Em segundo lugar, Felman sugere uma chave para a compreensão das reações, sempre carregadas de certo pathos, à leitura da novela. $\mathrm{O}$ que a comentadora percebe é que: a coisa mais escandalosa sobre essa estória escandalosa é que nós somos forçados a participar do escândalo, que a inocência do leitor não pode permanecer intacta: não há tal coisa como um leitor inocente deste texto. Em outras palavras, o escândalo não está simplesmente no texto, ele reside em nossa relação com o texto, no efeito do
* (Paes, José. "Até o último fantasma: a representação do fantástico em Henry Ja. mes". Ob. cit.: 174).

" Fadiman, Clifton. "Intro duction" e "Notes". Em: Ja mes, Henry. The short stories of Henry James. New York: Random House, 1945: XV).

- (Martin, Purdon. "Neuro. logy in fiction: The turn of the screw", British Medical Journal, 4, 1973: 717-21).

- (Sacks, Oliver. O homem que confundiu sua mulher com um chapéu. São Paulo: Círculo do Livro, 1985: 255).

(Felman, Shoshana. "Turning the screw of inter pretation". Ob. cit.: 118)

* (Freud, Sigmund. "Sobre el psicoanálisis 'silvestre"” [1910]. Em: Obras completas, vol.11. Buenos Aires: Amorrortu, 1994.) 
* (Felman, Shoshana. "Tur ning the screw of inter pretation". Ob. cit.: 97.)

" (James, Henry. A outra volta do parafuso. Ob. cit.: 127).

" (Felman, Shoshana. "Tur. ning the screw of inter. pretation". Ob. cit.: 107). texto sobre nós, seus leitores: o que é ultrajante no texto não diz respeito simplesmente àquilo do que o texto está falando, mas àquilo que ele faz falar em nós.*

Em terceiro lugar, seguindo a sua própria recomendação metodológica, Felman se concentra sobre uma passagem inicial de The turn of the screw, reproduzida abaixo, na qual um dos personagens que "em torno do fogo" escutavam a "história estranha contada, numa véspera de Natal, em uma velha casa", manifesta o desejo de saber um pouco mais sobre a nova preceptora:

- Por quem ela estava apaixonada?

- A história o dirá - ousei responder.

- Oh, mas não posso esperar a história!

- A história não o dirá [...]. Pelo menos não o fará de uma maneira literal, vulgar.*

Sobre esse trecho da novela, especialmente sobre a idéia de uma narrativa "literal" ou "vulgar", Felman nota que, de acordo com Henry James, o que tornaria pouco acurada determinada leitura de The turn of the screw não seria o fato de estar "incorreta ou falsa", mas sim o seu apelo a uma literalidade explícita, relacionada por ele a um certo sentido de vulgaridade. Diz Felman:

O vulgaré o literal, tanto quanto é o inequívoco. O literal é "vulgar" porque freia o movimento constitutivo da significação, porque bloqueia e interrompe o processo infinito da substituição metafórica. [...] A vulgaridade que James procura, acima de tudo, afastar é aquela da linguagem cujo discurso é plano e direto e cujas reservas de silêncio foram abolidas; é aquela de um texto inerentemente incapaz de silêncio, inerentemente incapaz de sustentar o seu próprio vocabulário.*

Não resta dúvida de que o ponto de vista de Felman é derivado da análise crítica realizada por Henry James de seu próprio texto em seu livro de anotações, em sua correspondência e, sobretudo, em seu prefácio ao volume XII de The New York edition of Henry James ${ }^{10}$.

${ }^{10}$ Como informa Pen: “Em $1900[\ldots]$ a Scribner’s propôs a Henry James reunir as suas obras numa edição de luxo, esse tipo de compilação estava no auge do sucesso. [...]. 'Eu particularmente gostaria de chamá-la Edição de Nova Tork', escreveu ele à Scribner's [...]. À coleção, que foi chamada nos Estados Unidos de Os romances e contos de Henry James. Edição de Nova Tork, James dedicou quase 
Nesse prefácio, em nenhum momento ele fornece argumentos seguros para um ou outro conjunto interpretativo. Ao contrário, interessa a James sobretudo manter a ambigüidade interpretativa, liberando a leitura para impressões e compreensões autônomas ${ }^{11}$. Como sublinha Edel:

James revelou em mais de uma ocasião como buscava propositadamente a ambigüidade, de forma que o leitor pudesse imaginar seu próprio "horror" - baseando-se na teoria de que um pesadelo é mais horripilante para a pessoa que o sonha. Dessa forma, preparou o terreno para uma invulgar colaboração entre autor e leitor. [...]

O que James adicionou ao conto fantástico foi na realidade uma série de profundos estudos acerca das modalidades da angústia humana - da capacidade que têm os homens para temer a si próprios, com fantasmas de sua própria invenção."

Virginia Woolf também acerta o alvo em seu ensaio crítico sobre as estórias de fantasmas de James:

cinco anos de sua vida. Tratava-se de uma realização ambiciosa. James revisou todos os 11 romances e 52 contos e novelas incluídos na obra. Trabalhou com afinco, colando cada página de cada um de seus livros numa folha em branco, bem maior. Nas margens, inseria suas extensas modificações. [...] Em muitas estórias, introduziu alterações em quase todo parágrafo. Inseriu e retirou trechos inteiros. Incluiu novas cenas. Apresentou mudanças que alteraram não só o caráter, mas também as características dos personagens. [...]. Enfim, James escreveu os prefácios. A idéia estava presente desde o início. Ainda na primeira carta enviada acerca do assunto a Charles Scribner (seu agente literário), explicava: 'A idéia do sr. James é escrever para cada volume um prefácio de uma qualidade bastante íntima […] não há dúvida de que um prefácio como esse faria crescer muito o interesse pelos livros'. Os prefácios foram ditados à última secretária de James [...] entre 1906 e 1908. É famosa a frase de James [...] sobre os prefácios: 'Eles são em geral', o escritor observou em carta ao romancista e editor W. D. Howells, 'uma espécie de apelo à Crítica, ao Discernimento, em linhas que não sejam incipientes - algo contra a ausência geral dessas coisas no mundo anglo-saxão [...]. Reunidos, eles devem, todavia, formar um tipo de manual abrangente ou vade-mécum para os aspirantes em nossa árdua profissão". Pen, Marcelo. "Introdução e notas". Em: James, Henry. A arte do romance: antologia de prefácios. São Paulo: Globo, 2003: 17-21.

${ }^{11}$ No filme The others, que se não é exatamente uma adaptação da novela de H. James apresenta muitos elementos jamesianos, está presente a técnica da ambigüidade interpretativa. Em uma entrevista, o diretor expõe suas idéias a esse respeito: "Para mim, deixar algo a cargo da imaginação é a essência do horror real. O horror mexe com as ansiedades, obsessões e paranóias latentes em nossas consciências. Desperte estes sentimentos primais e você transportará o espectador de volta aos cantos mais escuros dos medos de infância - de volta para aquele arrepio na espinha que só pode ser descrito como terrivelmente maravilhoso". Amenábar, Alejandro. The others, Estadou Unidos/Espanha: Miramax, 2001. 
*(Woolf, Virginia. "The ghost stories" [1921]. Em: Edel, L. Henry James: a collection of critical essays. Ob. cit.: 53-4).

* (James, Henry. "Prefácio a 'Os papéis de Aspern" [1909]. Em: A arte do ro mance: antologia de prefácios. São Paulo: Globo, 2003: 235).

" (Ibid.: 231).

* (: 232)
$\mathrm{O}$ que acontece se pegarmos para ler The turn of the screw um pouco antes da hora de dormir?

Talvez seja o silêncio aquilo que primeiro nos impressiona. Tudo em Bly é tão profundamente quieto. [...]. Nós tememos alguma coisa inominada, alguma coisa, talvez, em nós mesmos. Em suma, (antes que consigamos adormecer) acabamos por acender as luzes. Mas se examinarmos em segurança a estrutura da estória, notamos o quão magistralmente ela é montada, como cada frase se estende, cada imagem preenche, como o mundo interno se beneficia da robustez do externo, como beleza e obscenidade se coadunam cavando o seu caminho até as profundezas - até que possamos nos apropriar daquilo que permanece inexplicado. Devemos admitir que Henry James saiu-se vitorioso. Aquele velho cavalheiro sentimental, sofisticado e cortês ainda pode nos fazer ter medo do escuro."

Mas ninguém conseguiu ser tão claro em seus propósitos quanto o próprio Henry. Em seu prefácio, ele inicia pela crônica da elaboração do texto e, em especial, pelo cálculo técnico para a obtenção do efeito desejado. Pode ser surpreendente, e para alguns até um pouco chocante, a declaração de James de que The turn of the screw é "uma pura e simples peça de engenho, de frio cálculo artístico", e que uma de suas motivações para escrevê-la teria sido "fisgar os não facilmente fisgáveis (fisgar o mero tolo não era senão uma 'diversão' de pouca monta), o calejado, o desiludido, o rabugento"*. Mas é extremamente interessante o caminho que ele percorre, dourando e ornamentando um "grão" 12 de estória até a obtenção do êxito final - uma "flor tão completamente desabrochada da fantasia suprema"*. Seu método de ornamentação foi simples. Primeiro, valorizar a exigüidade do grão que tinha em mãos: "À superfície não havia muito, mas outro grão, entretanto, teria estragado a preciosa pitada, destinada a seu propósito"*. Segundo, tomar plenamente o grão e, a partir dele, "permitir à imaginação uma absoluta liberdade de ação, [...] convidá-la a agir num campo perfeitamente aberto, sem nenhum controle 'externo' envolvido, nenhum padrão do típico,

${ }^{12}$ Um grão, ou germe, no vocabulário de Henry James, significa um assunto, uma idéia inicial, uma imagem, uma lembrança, enfim, um ponto de partida para o início da redação de seus contos, novelas e romances. Em Notebooks, é possível notar como um assunto, em sua forma primeira de grão, progressivamente ganha importância na dinâmica de seu método de criação artística. Matthiessen, F. Henry James: the major phase. New York: Oxford, 1963. 
do verdadeiro ou do terrível "satisfatório"* Até que, em um dado ponto de seus vôos imaginativos, ele se dá conta de que, se para sua estória "funcionar" ele deveria incumbir as aparições espectrais "da horrenda tarefa de fazer a situação exalar o ar da Maldade”, esses personagens não poderiam ser agentes de nenhuma brutalidade, imoralidade ou infâmia específicas, tendo sido este o seu achado genial. Para que sua estória atingisse os fins visados, James deveria construí-la de modo a deslocar o eixo da interpretação para o leitor; o texto não revela tudo; ao contrário, serve apenas de suporte às fantasias do intérprete, como Henry confidencia na seguinte passagem:

Do que [...] eu tinha de transmitir a sensação? De ele ser, o par assombrado, capaz, como se diz, de tudo - ou seja, de exercer, com respeito às crianças, aquela pior ação a que poderíamos conceber sujeitas pequenas vítimas tão sugestionáveis. O que seria então, refletindo, essa concepção extrema? - quesito esse para o qual a resposta admiravelmente surgiu. Não há, nesse caso, nenhum absoluto elegível do malfeito; este se mantém relativo a cinqüenta outros elementos, uma questão de apreciação, especulação, imaginação - essas coisas, além disso, muito à luz da experiência do espectador, do crítico, do leitor. Basta tornar bastante intensa a visão geral que o leitor tem do mal, calculei [...], e sua própria experiência, sua própria imaginação, sua própria compaixão (pelas crianças) e horror (pelos falsos amigos delas) lhe fornecerão, de forma satisfatória, todos os pormenores. Faça-o pensar no mal, faça-o pensar por si, e você estará livre das frágeis especificidades.*

É preciso notar que, no prefácio, James concentra a sua análise sobre apenas um dos aspectos da maldade bafejada pelas aparições, a saber, o mal supostamente infundido por elas às crianças. É provável que a ênfase sobre esse tópico, tendo James podido debruçar suas análises sobre outros possíveis, deva-se ao fato de que, na época de publicação do texto, o foco de reação dos leitores e críticos tenha incidido sobre os aspectos morais da novela. Citamos algures parte representativa dessas reações e, na verdade, o próprio Henry se divertiu com elas, reconhecendo em seu tom afetivo e excessivo algo que dizia mais respeito aos leitores que a ele mesmo: "De grande interesse para o autor, entrementes - e, do mesmo modo, um tema para o moralista -, é a reação ressentida e simplória do leitor entretido, abundantemente abastecido com o sentido da situação. Ele inflige sua abundância, 
moralmente, sobre o artista - que só se apegou a um ideal de perfeição"*

Mas quais seriam, então, os "cinqüenta outros elementos" aos quais o Mal se mantém relativo? Ou, para falar em termos gerais, quais seriam as "várias possibilidades", aludidas por Dupee, de interpretação dos fantasmas de The turn of the screw, em uma história cujas análises literárias deslizam continuamente entre o pólo da patologia e o pólo do fantástico?

Tomando parte no jogo interpretativo, reportaremo-nos, então, a outro texto. Não uma novela, mas uma conferência transcrita e publicada também em 1898 por um James. Não por Henry, mas por seu irmão mais velho, William. Trata-se de Human immortality: two supposed objections to the doctrine. $\mathrm{O}$ argumento central dessa conferência é, resumidamente, o de que a idéia de imortalidade é compatível com aquela outra que afirma ser o pensamento uma função do cérebro ${ }^{13}$. Não se trata, portanto, de uma defesa lato sensu da imortalidade humana, mas apenas do combate à suposição científica, bastante popular, que vincula a morte cerebral à extinção de nossa vida espiritual.

William James, no epílogo de Psychology: briefer course*, torna equivalentes o ponto de vista do senso comum e o das ciências naturais, ao afirmar que a crença na suposta incompatibilidade entre a permanência de alguma forma de vida mental e a extinção física de um organismo humano se dá por uma má compreensão, por parte dos neurofisiologistas, do modo pelo qual o cérebro condiciona a mente. Estes tenderiam a dar importância exclusiva à "função produtiva"

${ }^{13}$ Neste ponto, William James adota essa concepção das relações entre o cérebro e a mente por razões argumentativas puramente estratégicas. As duas idéias contidas na afirmação "Thought is a function of the brain", quais sejam, o dualismo mente e corpo e o reducionismo fisicalista, são contraditórias com a radicalidade de algumas de suas concepções. Assim, James anota que, embora se expresse nessa conferência em termos dualísticos, considera-se livre para, "em qualquer ocasião posterior fazer uma tentativa, caso deseje, de transcendê-los e utilizar categorias diferentes”, o que, de fato, fará em outros escritos. Cf. James, William. "Human immortality: two supposed objections to the doutrine" [1898]. Em: James, William. Selected essays. New York: The Library of America, 1898: 1106). Ainda sobre este ponto, Andrieu destaca que, embora James seja visto por muitos teóricos das neurociências como uma espécie de pioneiro do reducionismo fisicalista, sua posição é não apenas contrária, mas sofisticada em seus argumentos antireducionistas. Cf. Andrieu, Bernard. "S. Freud et W. James: déplacements de la psychophisiologie”, Revue Internationale de Psychopathologie, n. 3, 1994. 
cerebral, negligenciando as funções "permissiva” e "transmissiva” do cérebro. Sobretudo a última função é útil no esclarecimento do argumento jamesiano pró-imortalidade. Nela, algum tipo de matéria ou energia já existente é remodelada, constituindo um novo formato material ou arranjo energético. À guisa de ilustração, William James recorre a algumas analogias, como a da luz que transpassa algum instrumento óptico: "No caso de um vidro colorido, um prisma, ou uma lente refratora, temos a função transmissiva. A energia da luz, não importa como foi produzida, é separada e limitada em cor pelo vidro, e, pela lente ou prisma, determinada em uma certa linha e forma"** Outra boa ilustração é dada pelas experiências que levaram à descoberta das partículas subatômicas mésons pi e mi. Esse exemplo parece especialmente útil por vir de um campo tão explicitamente fisicalista como o da física hard. Desse modo, opõe resistência a possíveis críticas de cepa cientificista que tendem a ver nessas idéias espectros esotéricos.

A história da descoberta é interessante e envolve o físico brasileiro Cesar Lattes.

Em 1935, foi proposta, teoricamente, a existência do méson, partícula que seria responsável pela estabilidade nuclear, sendo que "fora do núcleo atômico, os mésons sobreviveriam por apenas um bilionésimo de segundo, desintegrando-se em seguida"*.

Em 1937-8, encontrou-se, experimentalmente, o suposto méson. "Verificou-se, porém, que essa partícula não tinha o comportamento previsto" já que não era capturado “com facilidade pela matéria (podendo) atravessar centenas de núcleos atômicos sem sofrer nenhuma alteração”.

Algum tempo antes, a equipe, da qual Lattes fazia parte, havia observado os traços de partículas oriundas de raios cósmicos deixados em chapas especiais. "Um evento os impressionou em especial. Era o traço de um méson, que diminuía a velocidade e parava, dando origem a um novo traço”. As peças do quebra-cabeça foram se juntando e pesquisas posteriores revelaram a existência de dois tipos de partícula: um corpúsculo primário - o méson pi - mais pesado e responsável pela força nuclear, e um corpúsculo secundário à passagem pelo núcleo atômico - o méson mi.

$\mathrm{O}$ que faz desse capítulo importante da história da física algo com valor de exemplo para a teoria transmissiva de
*(James, William. "Human immortality: two supposed objections to the doutrine" [1898]. Em: Selected essays. New York: The Library of America, 1898: 1109-10).

" (Arantes, José. "O brasi. leiro que o Nobel esqueceu", Scientific American Brasil, ano 1, n.1, junho de 2002: 31). 
"(James, William. "Human immortality: two supposed objections to the doutrine". Ob. cit.: 1113.4)
" (Flanagan, Owen. "Cons. ciousness as a pragmatist views it". Em Putnam, R. (ed.). The Cambridge compa nion to William James. Cam bridge: Cambridge Univer sity Press, 1997: 42).
William James é a imagem de raios cósmicos atravessando um determinado núcleo atômico e fazendo com que um méson se transforme em outro, isto é, algo preexistente (a energia presente nos raios cósmicos) produzindo, pela interação nuclear, "um novo traço" de matéria.

No caso da vida mental ${ }^{14}$ ocorreria algo semelhante. Seguindo William James, haveria um fluxo mais geral da consciência, ou do pensamento, sem necessariamente estar sob a forma de uma consciência personalizada. Esse fluxo de pensamento mais amplo pode ser concebido como uma massa mental única, o que corresponderia, grosso modo, a uma espécie de idealismo transcendental ou um conjunto de mentes separadas, pouco importa. O fundamental para a teoria transmissiva é imaginar a presença de alguma coisa no mundo que "transcenda nossas mentes - que conseqüentemente venha de algo mental que preexista, e seja maior que elas mesmas"*. Esse algo mental preexistente, através de alguma forma de interação com o cérebro, seria limitado, plasmado ou formatado como aquilo que se convencionou chamar vida mental ou mente individualizada. A morte cerebral não implicaria, assim, a extinção do pensamento, e sim a extinção de uma relação específica: a interação de um cérebro particular possuído por um indivíduo específico com um fluxo de pensamento que não se extingue e, portanto, pode interagir com outros organismos possuidores de cérebros. Flanagan resume da seguinte forma os pontos principais da conferência de 1898: [...] se pensamento é uma função do cérebro no sentido de que para seres com corpos ("embodied beings") o cérebro permite e/ ou transmite pensamento, se ele é mais um conduto que um produtor, então não há incoerência de que pensamento, incluindo o fluxo do pensamento ("the stream of thought"), pode ser (1) de uma qualidade metafísica diferente daquela do cérebro, a qual (2) interage com o cérebro enquanto nós estamos vivos, e que (3) absorve e retém a identidade, personalidade e memórias constitutivas nesta interação, e finalmente (4) pode continuar seguindo sem o cérebro."

A essa altura já se pode notar de que modo algumas das idéias de William James podem ser úteis na formação de um

${ }^{14}$ Como nota Flanagan, "James freqüentemente escreve como se mentalidade fosse sinônimo de consciência ou de vida mental consciente”. Flanagan, Owen. The science of mind. Cambridge: MIT, 1991: 25. 
terceiro conjunto de interpretações para The turn of the screw. Se há mesmo uma vida mental preexistente, e subseqüente à nossa existência individual, então nada impede que algumas pessoas/personagens tenham a capacidade não de se comunicar com os mortos ou com o além, mas de manter interações menos comuns com esse fluxo de pensamento. $\mathrm{Na}$ verdade, William James manteve interesse vívido por certas classes de fenômenos misteriosos, como atestam alguns fragmentos biográficos ${ }^{*}$ e, principalmente, como se pode deduzir da presença significativa desses assuntos em sua produção teórica. Com efeito, na conferência em questão, James relaciona sua teoria transmissiva a fenômenos como conversões religiosas, curas instantâneas, premonições e aparições:

[…] eles (os fenômenos) não precisam ser 'produzidos' - eles existem prontos no mundo transcendental, e tudo o que é necessário é um rebaixamento anormal do limiar cerebral para deixá-los atravessar. [...] Nós precisamos supor apenas a continuidade de nossa consciência com um oceano-mãe $\mathrm{e}^{15}$, para levarmos em consideração ondas excepcionais ocasionalmente desaguando na represa.* $^{*}$

Mas o interesse de W. James pelo sobrenatural não é exatamente o interesse pelo oculto. Ao contrário, para ele, o estudo dessas vivências peculiares deve servir não ao fetiche ocultista, mas à proposta de redescrição clarificadora das possibilidades de contato com elementos extraconscientes que, embora "fora" da consciência, ainda estariam dentro dos, por assim dizer, domínios do eu. Quando William James escreve, em The varieties of religious experience, que "a pessoa consciente é contínua com um self mais amplo”, ou que "os limites mais distantes do nosso ser mergulham [...] numa dimensão completamente outra daquela do mundo sensível e meramente "inteligível”, ele dirige o foco de sua investigação para o que, em momentos distintos de sua obra, chama de fluxo do pensamento, de “oceano-mãe", de experiência pura ou, até mesmo, de "uma força maior". Em Varieties, há um trecho em que James traça, mais uma vez e de um modo sempre um pouco renovado, o esboço das relações do eu com a tal força maior:

Tudo o que os fatos requerem é que a força possa ser simultaneamente distinta e maior do que nossos selves conscientes. Qualquer

15 "Mother-sea" no original.
- (Delabarre, Edmund. "A student's impressions of James in the late'80's", Psychological Review, vol. 50, 1943: 125.34.)

"(James, William. "Human immortality: two supposed objections to the doutrine". Ob. cit.: 1118-9.) 
(James, William. The varieties of religious expe. rience: a study in human na ture [1902]. New York: The Library of America, 1987: 460.8.) coisa maior o fará, desde que seja grande o suficiente para que se confie em dar o passo seguinte. Ela não precisa ser infinita, nem precisa ser única. Ela pode mesmo ser apenas um self maior e mais divino do qual o self presente poderia ser, então, apenas a expressão mutilada, e o universo seria concebido como uma coleção de tais selves de diferentes graus de inclusividade sem que resultassem em nenhuma unidade absoluta.

Retornar à novela de Henry James após essa digressão teórica torna possível a redescrição das vivências da autora do manuscrito, bem como a oposição de um terceiro pólo interpretativo alternativo àqueles tributários da psicopatologia ou do macabro. Onde se via histeria ou psicose, veja-se a possibilidade de novas operações sobre uma existência mental expandida; onde, literalmente, viam-se fantasmas, veja-se um cérebro que permite o influxo de uma parte um pouco mais ampla do todo mental.

Lá, a coisa mudou de aspecto; lá, durante muitos dias aconteceu algo bastante singular. Havia horas, todos os dias [...] em que eu precisava isolar-me para pensar. Não que eu estivesse mais nervosa do que poderia suportar $[\ldots]$ a verdade que eu tinha agora de enfrentar era, clara e simplesmente, a de que de forma alguma eu poderia identificar o visitante com quem havia entrado em contato de modo tão inexplicável e, no entanto, parecia-me, tão íntimo. [...]

Contudo, dei-lhe tempo para que reaparecesse. Digo tempo mas quanto tempo? Não é possível dizer, hoje, quanto tempo duraram essas coisas. Sem dúvida, perdera a noção de sua medida: não podiam ter durado tanto quanto me pareceu. [...]

Tinha absoluta certeza de que eu tornaria a ver o que havia visto, mas algo em meu íntimo me dizia que, oferecendo-me corajosamente como único sujeito de tal experiência, aceitando-a, provocando-a $[\ldots]$

Eu era uma tela...*

Esses excertos, e mesmo os anteriormente citados em referência aos dois primeiros grupos de interpretação, passam a ser vistos com outros olhos. Para além das considerações que se enriquecem com a parceria teórica de William James, que não desloca para o sobrenatural as experiências vivenciadas, mas lhes dá dimensão híbrida de experiência científica e especulação metafísica - "oferecendo-me corajosamente como único sujeito de tal experiência, aceitando-a, provocando-a” -, ressalte-se também a idéia de que a personagem do conto se assume no domínio da ficção: "Eu era uma tela”, na 
qual o que se pinta tem outras tintas, texturas e dimensões para além da referencialidade imediata do real.

Mas, antes disso, deve-se notar que a passagem do pólo interpretativo psicologizante para o terceiro pólo tem outra conseqüência muito importante: o abandono do modelo intrinsicalista da vida subjetiva em favor de um modelo de funcionamento psíquico externalista. Implicitamente, a diferença entre os dois modelos aparece também nas diferentes interpretações da obra de Henry James feitas por Paes e por Carpeaux*.

Paes, ao afirmar que "o realismo de James é psicológico", opera uma distinção entre o que chama de "interioridade dos personagens" e o "mundo dos fatos", entendendo, por assim dizer, a atuação dos "fatos" sobre a "interioridade" como "impressões". Carpeaux, por sua vez, ao explorar o caráter diáfano e atemporal dos personagens jamesianos, parece esfumaçar distinções muito rígidas entre o que é interno ao sujeito e o que é próprio do mundo. Assim, Paes surge mais aferrado ao modelo intrinsicalista, enquanto Carpeaux sugere menos compromisso com tal modelo e alguma sintonia com o modelo externalista da vida psíquica. Dito de outro modo, passa-se de um modelo de eu caracterizado por conceitos como os de representação, espaço interno e privacidade ôntica para um modelo que recusa uma condição sine qua non do modelo intrinsicalista: o dualismo mente-corpo ou, ainda, a dualidade entre o eu e o mundo. William James inspira uma versão desse segundo tipo de modelo por narrar em novas bases as relações ou, antes, as superposições, ou, em uma palavra, a fluidez, entre o eu e esse fluxo de pensamento não personalizado. Ele desarticula a imagem de um eu feito de extratos ou de camadas progressivamente profundas, pela apresentação de outras imagens descritas em um vocabulário no qual as referências a profundidades, a subterrâneos ou a sedimentos mais íntimos estariam ausentes.

No ano de 1898, há mais similaridades no que escreveram os irmãos James do que se poderia pensar em um vislumbre ligeiro.
"(Paes. "Até o último fan. tasma: a representação do fantástico em Henry Ja. mes". Ob. cit. Carpeaux, Otto Maria. História da literatura ocidental, vol. V. Rio de Janeiro: O Cruzeiro, 1963). 
Palavras-chave

A volta do parafuso

Henry James

William James

Key words

The turn of the screw

Henry James

William James

Mots-clés

The turn of the screw

Henry James

William James

\section{Guilherme Gutman}

Doutor em Saúde Coletiva pelo Instituto de Medicina Social da Universidade do Estado do Rio de Janeiro. Publicou, entre outros, o artigo “Todas as vias levam ao hábito? Introduzindo William James” na Revista Latinoamericana de Psicopatologia fundamental (dezembro de 2004), acompanhado da sua tradução de um capítulo do livro Psychology: briefer course, de William James.

\section{Resumo}

A novela The turn of the screw de Henry James foi objeto de intensa atividade de crítica literária. Ao longo de cerca de um século, dois grandes grupos interpretativos se tornaram referência obrigatória sobre o assunto. O primeiro deles é composto, grosso modo, de resenhas, artigos e livros que inserem a novela na linha da narrativa fantástica; já o segundo grupo interpretativo pode ser nomeado de psicologizante, ao sugerir que The turn of the screw não é uma estória de fantasmas, mas o estudo em ficção de um caso de adoecimento psíquico. Nessa linha de debates, o autor procura introduzir uma terceira via interpretativa que se fundamenta em alguns aspectos técnicos da obra teórica de William James, irmão de Henry.

\begin{abstract}
The Henry James's short story The turn of the screw was object of full criticism activity. Along nearly a century, two major interpretative groups become an obligatory reference. One of the groups, composed of reports, papers and books, inserts Jame's short story in the fantastic narrative line; the second interpretative group is caracterized by psychological emphasis, suggesting that The turn of the screw isn't a ghost story, but a study in ficction of psychical suffer. In that line of discussions, the author looks to introduce a third way of interpretation wellgrounded by some technical elements of William James's works, brother of Henry.
\end{abstract}

\section{Résumé}

La nouvelle de Henry James, The turn of the screw, a été l'objet d'une activité intense de critique littéraire. Tout au long d'un siècle, deux groupes d'interprétation sont devenus une référence obligatoire en ce que la concerne. Le premier étant composé, grosso modo, de compte-rendus, d'articles et de livres qui proposent l'insertion de cette nouvelle dans la catégorie du fantastique; le second, qui pourrait être conçu comme psychologisant, propose à son tour de voir, non plus une histoire de fantômes, mais l'étude d'un cas de maladie psychique. L'auteur de cette étude cherchera à introduire une troisième voie d'interprétation, décelant dans le corpus textuel quelques aspects techniques de l'oeuvre théorique de William James, frère de Henry. 